\title{
Direito e gerenciamento nas administrações públicas - Notas sobre a crise e renovação dos respectivos paradigmas
}

\author{
Joan Prats i Catalá
}

\section{Introdução}

Uma das transformações que mais chamam a atenção nas Administraçõcs Públicas do nosso tempo (anos $80 \mathrm{c}$ atuais 90 ) foi c continua sendo a invasão súbita do gerenciamento $\mathrm{em}$ todos os tipos $\mathrm{c}$ níveis administrativos do mundo.' $\mathrm{O}$ fenômeno está gerando incvitável confusão. Principalmente porque, ao contrário do que aconteceu com "as modernas técnicas de gestão" das reformas administrativas dos anos 50 e 60, o gerenciamento não aparece agora como um mero agregado tecnocrático à ordem tradicional da legitimidade legal das Administra̧̧ões, mas sim como portador de um fator próprio de legitimidade, representado pelos valores de eficácia e cficiência. Além do mais, estes valores deixaram de ser uma mera invocação retórica que justifica o poder tecnocrático para se configurar como legitimos valores proclamados constitucionalmentc e exigidos socialmentc como condição de legitimidade.

Desta forma, resulta que à legitimidade tradicionalmente exigida das Administrações Públicas tem sido acrescentada não somente a exigência dos valores da eqüidade social $\mathrm{c}$ da participação, traçados pela transição ao Estado Social c Democrático de Direito, mas, nos últimos anos, a legitimidade das Administrações Públicas tem exigido, também, a eficácia c a eficiência no uso dos recursos públicos, o que responde a uma necessidade $\mathrm{c}$ a uma demanda social derivada, entre outros motivos:

Joan Prats i Catala ć doutor em Dircito Público, diretor do programa sobre transição econòmica e governabilidade entre a ESADE a a Universidade das Naçdes Unidas 
a) do fato de que as Administrações controlam enormes recursos públicos (entre $35 \%$ c $50 \%$ do PIB nos países da OCDE), que não são, afinal de contas, subtrações fiscais coativas dos patrimônios ou do potencial de renda privada e de cuja utilização sensata há que se prestar contas justas a toda sociedade que quiser se organizar decentemente;

b) da descoberta de que muitas políticas e programas públicos não têm os impactos cconômicos c sociais que justificaram formalmente a sua adoção, mas sim outros, inesperados ou perversos, muitas vezes vinculados ao fenômeno dos corporativismos econômicos, sindicais ou sociais, que não justificam, em termos de eficiência econômica nem de eqüidade social, a alocação de recursos c liberdade privada que as politicas e programas impuseram;

c) do fato de que a eficácia e a eficiência da gestão pública se transformaram hoje $\mathrm{cm}$ uma condição de sobrevivência $\mathrm{c} \mathrm{cm}$ um fator ou diretriz de reforma, não só do próprio Estado Social, mas para o alcance da competitividade $\mathrm{c}, \mathrm{cm}$ conseqüência, do próprio desenvolvimento econômico de cada país, sem o qual não cabe nenhuma politica social sustentável. ${ }^{2}$

A confusão provém também do fato de que o gerenciamento ou, se assim o preferir, as ciências da gestão, longe de responder a um paradigma bem estabelecido, se expressa $\mathrm{cm}$ conteúdos $\mathrm{e}$ formas plurais, às vezes contraditórios $\mathrm{e}$, além disso, sem uma corporação acadêmica especializada que possa reivindicar o monopólio ou a hegemonia intelectual sobre o campo. Na organização ministerial do novo arbor scientiarum realizada na Espanha por ocasião da distribuição do orçamento universitário entre as diferentes farnilias da burocracia acadêmica, o gerenciamento público só pôde ser visualizado como um componente da Ciência da Administração, a qual nem sequer tem reconhecida sua substantividade, reduzindo-se a mero apêndice do Direito Administrativo c da Ciência Política.

Desta forma, não é de se estranhar que a demanda pública de racionalização gerencial tenha sido orientada para as empresas de consultoria c escolas de negócios. $\mathrm{E}$ as respostas trazidas por estas, independentemente de scus méritos, não deixaram de criar confusão. Especialmente por que, como era quase inevitável, pretendeu-se transferir mecanicamente os princípios c técnicas de gerenciamento empresarial no ambiente privado à gestão de bens $\mathrm{c}$ serviços públicos cm situaçōes de "não-mercado" e com forte componente de "autoridade". Em outras palavras, tem sido ignorado, geralmente, que o padrão "institucional" da gestão pública $\mathrm{e}$ da gestão privada respondem a principios, valores e normas diferentes. Tudo isso não deixou de produzir alguns excessos que justamente hoje aparecem, pois a reivindicação, 
por exemplo, de maior liberdade de atuação para os administradores públicos, do argumento de se fazerem iguais aos administradores privados, tem produzido a anulação dos velhos e estúpidos sistemas de controle, sem substituí-los, porém, por um novo e verdadeiro sistema de prestação de contas e de responsabilidade. $\mathrm{O}$ desconhecimento ou esquecimento das restrições constitucionais e institucionais da gestão pública tem levado muitos políticos e gerentes inescrupulosos a verem no gerenciamento o saber legitimado, não de um novo e mais eficiente sistema de responsabilidade, mas, sim, de uma maior liberdade de ação, que, aberta, pode tão somente incrementar a arbitrariedade do poder c, com ela, o potencial de corrupção. ${ }^{3}$

A invasão súbita do gerenciamento está transformando as Administrações em torres de Babel, dada a pluralidade de enfoques, linguagens, tecnologias, modelos conceituais e até valores que vão penetrando a organização, a ação administrativa, o pensamento e a linguagem dos administradores. Contudo, algumas causas da confusão parecem que estão, felizmente, sendo superadas. Merece destaque, particularmente, o crescente abandono da ilusão sem fundamentos de que o gerenciamento empresarial privado pode se transferir, de forma imitativa c mecânica, às Administrações Públicas. Esta ilusão continua presente na prática (n€m sempre ingênua) de muitas empresas de consultoria e na cabeça de alguns politicos e administradores que continuam, imprópria, mas nem sempre ingenuamente, acreditando que o gerenciamento é um repertório de técnicas de gestão, de perfeito intercâmbio, entre as empresas e as Administrações Públicas. Perante tudo isso, porém, a comunidade científica internacional definiu-se claramente, pois, como costuma dizer Paulo Motta, entre a gestão pública e a privada acontece o mesmo que entre os homens e as mulheres: coincidem em $90 \%$, mas o que importa é a diferença de $10 \%$ existente. $\mathrm{O}$ crescente reconhecimento cientifico internacional do "Gerenciamento Público" decorre da afirmação de uma empresa intelectual específica, que ultrapassa muito o mero diálogo e a translação ou imitação do gerenciamento privado, já que responde a problemas especificos das Administrações Públicas cujo tratamento requer investigação, modelos conceituais e até mesmo técnicas de intervenção especificas.

Contudo, grande parte da confusão vem também da incapacidade de o Direito Administrativo entender c estabelecer um diálogo fecundo com o gerenciamento público, o que, afinal de contas, não tem nada de estranho, devido ao afinamento da corporação administrativa no paradigma "antidiscricionário". ‘ Uma das hipóteses que desenvolveremos é que a substantividade ou especificidade científica do Direito Administrativo, laboriosamente construida entre o último terço do século passado e o primeiro do atual, tem-se modelado $\mathrm{em}$ um paradigma que 
atende e resolve os problemas de Iegitimidade do Estado Liberal de Direito, mas que tem sido irrelevante e indiferente ao desenvolvimento do Estado Social c Democrático e resulta alheio, quando não contraditório, com o desenvolvimento da racionalidade gerencial pretendida pelo gerenciamento atual. O Direito Administrativo, todavia dominante, encontra-se aprisionado $\mathrm{cm}$ um paradigma que já não responde à dinâmica dos fatos, conduzindo à sua negação estéril c crítica, impedindo o diálogo fecundo com o gerenciamento público no modelo renovado de algumas Ciências da Administração, hoje mais necessárias que nunca devido às rápidas e profundas transformações a que está sendo submetido o setor público do nosso tempo. ${ }^{5}$

Um fantasma de insipidez percorre o Dircito Administrativo de todas as democracias ocidentais. Os fatos escapam c sua negociação conduz a um isolamento crescente. Frente ao paradigma tradicional e perante a incapacidade de conceber $\mathrm{c}$ responder às novas realidades com os instrumentos e os modelos conceituais tão laboriosamente construídos, denuncia-se de mancira tão irritada quanto estéril, a fuga incessante $\mathrm{e}$ incontida dos fatos sem conseguir desta forma comover a quase ninguém. Provavelmente Mintzberg, e muitos outros estão certos quando dizem estar cada vez mais convencidos de que os seres humanos vêem o que acreditam e não o contrário. Continua ainda sendo útil a apreciação de Kuhn de que nossas máquinas de enxergar são os nossos paradigmas e que quando um paradigma não mais permite integrar novos fatos nem dar resposta aos novos problemas, simplesmente estão assentadas as bases de uma tipica revolução científica. ${ }^{6}$

Todo este processo geral é mais notório no caso espanhol. Basta mostrar que a primeira função de racionalização da autocracia franquista, realizada pelo Dircito Administrativo, foi cocrente com o paradigma clássico, cuja razão histórica de ser tem sido, principalmente, garantir, mediante o controle judicial, as liberdades econômicas e a ordem social autônoma do mercado frente ao risco da arbitrariedade dos poderes públicos. O Direito Administrativo teve, sem dúvida, um papel importante pois, mesmo não tendo supcrado nos fatos o estágio da mera legalidade administrativa e certo liberalismo econômico, ajudou discretamente a racionalização do Estado e o desenvolvimento da autonomia da sociedade civil. Além disso, a confusão doutrinária consciente entre legalidade administrativa e Estado de Direito influcnciou ideologicamente a transição $\mathrm{cm}$ direção a este. Deve-se reconhecer com isso que, desde o reformismo franquista, o Dircito Administrativo ajudou também a assentar as bases jurídicas c econômicas da transição democrática espanhola. $\mathrm{O}$ paradoxo está no fato de que, quando se pensava que o paradigma do Dircito Administrativo havia conseguido seu pleno reconhecimento constitucional, uma séric de importantissimos fatos 
novos ou realidades impuseram transformações radicais no sctor público, que, além de não se encaixarem nele, questionam frontalmente o paradigma tradicional. ${ }^{7}$ Não se trata, portanto, de entrar no jogo absurdo de quem tem razão, nem das desqualificações. Os paradigmas científicos jamais serão eternos, $\mathrm{c}$ os que funcionam $\mathrm{cm}$ determinado contexto estão necessariamente destinados a ser substituidos por outros novos quando o contexto mudar radicalmente. O que está cm jogo não é nenhuma reclamação, mas a tarefa colctiva de redefinir a posição e o papel do Direito nas Administrações c na gestão pública de nosso tempo.

Entretanto, não se deve pensar que, a partir do gerenciamento se contemple confortavelmente a crise do Dircito Administrativo. As ciências do gerenciamento viveram uma crise interessantíssima e uma renovação de paradigmas c o gerenciamento público não é mais do que um paradigma emergente. Por isso, a oposição entre Direito Administrativo e gerenciamento constitui em si outra fonte de confusão que seria conveniente esclarecer. O Dircito Administrativo continua não querendo entender o gerenciamento, considerando-o, em resumo, como um repertório de técnicas de mera cxecução de decisões, com origem na empresa privada e de duvidoso ranço norte-americano. Pretende-se continuar ignorando que o gerenciamento representa hoje o saber teórico c prático mais reconhec do internacionalmente e que, longe de ser um repertório de receitas supostamente universais, ć um projeto intelectual c uma prática profissional fundamental no mundo das organizações. Por comodidade ou falta de visão corporativa não se quer conhecer as contribuições do gerenciamento à teoria de decisão, ao traçado organizativo, à gestão estratégica, à gestão financeira ou à dos recursos humanos, por exemplo. A conseqüência ć a não compreensão de uma séric de processos reais, que se denunciam como "fugas" c, o que ć pior, não se obtém uma sćric de conccitos e técnicas que permitiriam salvar velhos $\mathrm{c}$ irrenunciáveis valores do paradigma tradicional $\mathrm{c}$ os colocar em fórmulas novas, compativeis com os valores gerenciais da eficácia e da eficiência. ${ }^{8}$

Do ponto de vista do gerenciamento, o Dircito Administrativo é um fator de freio ou de bloqueio dos processos de racionalização gerencial. Não conhecendo outro Direito Administrativo que o do projeto antidiscricionário, o gerenciamento se espanta que se continuc a ver a discricionariedade como problema c não como a ocasião e oportunidade de se prestar serviço responsável aos interesses gerais. A desqualificação do Direito Administrativo pelo gerenciamento praticamente se transformou $\mathrm{cm}$ uma constante nas politicas administrativas da década de 80 . Basta um minimo de conhecimento do cotidiano administrativo para saber como vêcm c vivem o Dircito Administrativo os diretores públicos, e não somente na Espanha. Pode- 
se pensar que tal atitude é inerente a todo poder, que tenderá sempre a configurar como liberdades juridicas o que são meras jurisdições. Porém, a reprovação não é só politica, mas também é doutrinária. Por exemplo, para Loschak, dada a inevitabilidade e até mesmo a conveniência de diferentes graus de discricionariedade nos âmbitos do fazer administrativo, a manutenção do paradigma tradicional está convertendo a legitimidade em legalidade formal e transformando o Direito Administrativo $\mathrm{em}$ mero molde que não contribui $\mathrm{cm}$ nada ao exercicio positivo da discricionariedade, permitindo, paradoxalmente, a abertura de brechas no Estado de Direito, pelas quais a arbitrariedade é novamente introduzida no funcionamento dos poderes públicos. Crozier vê na racionalidade legal dominante a principal causa da oxtraordinária rigidez da Administração Pública e da paralisação das tentativas de adaptação da mesma. Willke fala dos custos de inadaptação do conceito tradicional de legalidade, custos que procedem não só da pretensão de uma normatização excessiva da vida administrativa, mas do processo de fuga de um regime administrativo que está de costas para as realidades da sociedade moderna. Os depoimentos poderiam continuar. Basta, então, citar Caillosse, que, fazendo cco ao debate promovido na França, menciona: "O Direito Público, que antes era um instrumento privilegiado de modernidade, considera-se hoje portador de uma ideologia oposta à inovação, que continua garantindo às Administrações um tratamento privilegiado, obstruindo a introdução de uma cultura empresarial c olhando com desconfiança iniciativas $\mathrm{em}$ favor da competitividade e rentabilidade. ${ }^{9}$

Porém, ao contrário do que se acredita, nenhum dos autores citados considera permanente ou sem salvação a oposição atual entre Direito e Gerenciamento das Administrações Públicas. Pelo contrário, advogam um restabelecimento radical dos pressupostos básicos do Dircito Administrativo tradicional que deve deixar de ver na discricionariedade o Cavalo de Tróia do Estado de Dircito, passando a considerá-lo um elemento fundamental da Teoria Administrativa moderna. Defendem também que o Direito deve contribuir para traçar o perfil, como instrumento de melhoria da eficácia e confiabilidade das políticas. ${ }^{10} \mathrm{Ou}$, conforme mostra Stecle, o Direito Administrativo há de subtrair-se da sujeição ou serviço dominante à prática privada da advocacia que o reduz a uma concepção de garantias e procedimentos, que não contempla outro objetivo que o da reforma da revisão judicial, para se concentrar na melhoria da adoção de decisões. " Neste mesmo "sentido, Davis, a partir da sua reconhecida liderança acadêmica, mostra que, na nova etapa do Direito Administrativo, "o foco da investigação mudará, passando da revisão judicial e das salvaguardas de procedimentos aos pretendidos $89 \%$ de procedimentos administrativos, 
para os quais tais salvaguardas e revisão são irrelevantes. O futuro está na melhor compreensão do exercício informal da discricionariedade scm revisão judicial".12

Estamos, então, diante de uma corrente doutrinária poderosa que, tanto do ponto de vista do gerenciamento como do Direito Administrativo, está propondo uma mudança de paradigmas capaz de estabelecer um diálogo fecundo que permita desenvolver novos padrões conceituais a partir dos quais seja possivel apreender e orientar as inevitáveis transformações do setor público. Simplesmente nos unimos a esta corrente. Contra as reações primárias de tantos administradores e gerentes, longe de ver entre o Direito e o gerenciamento uma relação contraditória, acreditamos firmemente que o mútuo reconhecimento, compreensão e intercâmbio, ć a condição (obviamente não suficiente) para a transformação qualitativa e sustentável de nossas Administrações Públicas. Considero ser um grave erro a atitude de menosprezar c marginalizar o Direito, manifestada em tantos programas e "modernizadores" administrativos que vivem uma grande confusão intelectual: tendo aprendido que "não se modifica a Administração por meio de Decretos", acreditam que é possível mudá-la à margem do Dircito. Atuando desta forma, não apenas provocam graves desajustes entre as práticas informais e a legalidade formal, com a conseqüente desordem c risco de arbitrariedade, mas fazem também com que grandes esforços de mudança acabem absorvidos pelas instituições formais vigentes, que a priori não aceitam o seu restabelecimento. ${ }^{13}$

Precisamos de uma renovação gerencial de nossas Administrações Públicas tanto quanto de uma renovação paralela e cocrente de seu Dircito. Ambos os processos devem avançar cunjuntamente e mantendo um diálogo permanente, pois respondem às exigências constitucionais igualmente indispensáveis do Estado Democrático e Social de Direito e dos principios de eficácia e eficiência. ${ }^{14}$ Tal diálogo não se produzirá sem tensões e até mesmo contradições, o que não é nada novo na história do Direito Público, que teve que se acomodar, sucessivamente, desde o inicial c irrenunciável princípio do Estado de Direito aos novos princípios constitucionais do Estado Social e Democrático, aos principios de eficácia e eficiência hoje igualmente irrenunciáveis. ${ }^{15} \mathrm{~A}$ grande tarefa atual parece ser, precisamente, a de encontrar o optimum histórico de equilibrio entre estes principios em tensão, o que implicaria tanto esforços de renovação do Direito Administrativo, como de claboração do gerenciamento especifico das Administrações Públicas.

Com a finalidade contribuir para evitar conflitos iniciais e ajudar a demarcar as tarefas citadas anteriormente, mostraremos uma série de hipóteses de partida, cujo desenvolvimento mais adequado terá que ficar, forçosamente, para outra ocasião. 


\section{Coincidência paradigmática de fundo entre o Direito Administrativo tradicional e o gerenciamento da ordenação científica}

O paradigma tradicional do Dircito Administrativo, resumido por alguns como o "projeto antidiscricional", não ć somente coerente, mas implica, necessariamente, o paradigma do gerenciamento representado pela teoria clássica da burocracia c da ordenação científica do trabalho. Em outras palavras, segundo os respectivos paradigmas iniciais, Direito e Gerenciamento, racionalidade legal e racionalidade gerencial das Administrações Públicas, não só não são contraditórios como também implicam um no outro e se sobrepõem mutuamente, como conscqüência de sua ascensão pelos mesmos pressupostos, valores, problemas c métodos. ${ }^{16}$

Esta hipótese corresponde a posições doutrinárias muito gencralizadas. Como menciona Arthurs, os pressupostos conceituais e percepções idcológicas do paradigma do Dircito Administrativo correspondem plenamente ao sistema de dominação Icgal-racional de Weber. ${ }^{17}$ Conforme assinala hoje a doutrina anglo-americana, com aparente unanimidade, a afirmação do dualismo entre a sociedade civil e o Estado, a crença na possibilidade de programar normativamente toda a ação estatal e a necessidade, por parte dos agentes econômicos, de garantir a máxima aplicação das decisões públicas situam o projeto intelectual do Direito Administrativo na produção c exccução correta das normas e na conscqüente redução do espaço da discricionaricdade, praticamente identificada com a arbitrariedade. ${ }^{18}$

Este projeto corresponde e envolve aspectos decorrentes da racionalidade burocrática webcriana $\mathrm{c}$ da ordenação cientifica do trabalho do primciro gerenciamento. Dão-se aqui por conhecidos o conceito c os traços do tipo ideal de burocracia weberiana. Basta mencionar quc, scgundo o próprio Webcr, a burocracia ć um tipo organizativo racionalmente superior a qualquer outro conhecido ("um mecanismo burocrático perfeitamente desenvolvido atua $\mathrm{cm}$ relação às demais organizações da mesma forma que uma máquina em relação aos métodos não-mecânicos de fabricação"), com o correspondente lógico de que o progresso administrativo passa pela tarefa de implantação universal do tipo burocrático, isto ć, de estruturar normativamente o universo dos comportamentos organizacionais. ${ }^{19}$ As normas organizativas, segundo Weber, podem ser jurídicas ou técnicas, mas o conhecimento e a aplicação de umas e outras exigem um conhecimento especializado, que é o próprio do burocrata ou 
administrador público que deve ser dotado de um estatuto jurídico especial, que reflita a nitida separação entre sociedade c Estado, política c administração. A leitura precipitada de Santi Romano realizada anos atrás por Sebastian Martin Retortillio ajudou a afirmação absurda da validade juridica de toda norma organizativa, levando-se desta forma $o$ modelo legalista da gestão pública a extremos sem paralelo nas Administrações comparadas.

A linha de pensamento organizativo conhecida como "ordenação ou organização científica do trabalho", embora rclacionada dirctamente com o problema da eficiência na organização $e$ não do poder na sociedade, coincide plenamente com os pressupostos do tipo ideal de dominação legal da concepção weberiana. ${ }^{20}$ Taylor compartilhava plenamentc a visão maquinicista da organização. Acreditava que esta, como qualquer outra parte da realidade, estava governada por regularidades definidas, por leis que podiam ser descobertas mediante a observação e a experimentação que, uma vez conhecidas, permitiriam determinar a forma de execução objetivamente melhor para cada tarefa. Estes pressupostos levavam necessariamente a separar o trabalhador do cargo, o plancjamento ou a normatização da execução c centravam a função das ciências do gerenciamento na descoberta de princípios organizativos e na geração de técnicas de gestão de pretenso valor universal, e baseavam a função dos dirigentes ou gerentes em cuidar da correta formulação c execução das normas e princípios organizativos.

Como se sabe, a sintese realizada por Woodrow Wilson da teoria burocrática e do ordenamento científico dará nascimento à Ciência da Administração norte-americana, que se moverá inicialmente tendo como base estes mesmos pressupostos. Wilson, em seu "Estudo da Administração Pública", estabeleceu quatro grandes premissas: a) a governação consiste $\mathrm{cm}$ dois processos separados: a política $\mathrm{e}$ a administração; b) a Administração pode e deve constituir o objeto de uma ciência diferente da politica; c) o estudo cientifico da Administração Pública conduz à descoberta de principios análogos ao das leis nas ciências fisicas; d) a aplicação de tais principios irá assegurar uma maior economia e eficiência. ${ }^{2 !}$

Esta concepção de Administração como racionalidade meramente instrumental ou técnica parece que foi tomada por Wilson da mesma tradição germânica do Estado orgânico que inspirou o grande trabalho de Weber. Suas raizes podem ser levadas até o panfleto de Kant de 1784 , intitulado "O que é a ilustração?", no qual sc celcbra a cmancipação da humanidade da opressão do mito $c$ da autoridade externa mediante o exercício da razão. Para Kant, a habilidade de tornar 
pública a utilização da razão constitui a medida da liberdade humana. Somentc o uso da razão na critica permite que os seres humanos possam transcender suas atuais circunstâncias, mediante a realização de juizos que aspiram à validade universal. Porém, na construção do Direito Administrativo c da Ciência da Administração norte-americana, mais do que a idéia de razão e o racionalismo de Kant, pesaram as construções hegeliana e weberiana da racionalidade. ${ }^{22}$

Hegel enfatizou também a habilidade dos seres humanos $\mathrm{cm}$ alcançar a liberdade mediante a accitação de deveres auto-impostos $\mathrm{c}$ fundamentados na razão. Porém, Hegel acreditava que o Estado moderno representava a auto-rcalização da razão, não como um idcal kantiano, mas como a conseqüência racional de toda a história anterior. $\mathrm{O}$ poder do pensamento critico torna o ser humano racional, porém, para Hegel, o que faz o mundo racional é o aparelho do Estado. Dai sua concep̧ão da burocracia como uma categoria universal de servidores civis capazes, ao mesmo tempo, de se sobreporem e mediarem as particularidades produzidas, incvitavelmente, pelas relações cconômicas de poder e pela competição por recursos sempre escassos. Como é sabido, a apreciação acrítica que Hegel fez da dominação burocrática $\mathrm{cm}$ sua própria sociedade transformou-se no ponto de partida da crítica de Marx ao próprio Hegel $\mathrm{c}$ ao aparelho estatal $\mathrm{em}$ geral. ${ }^{23}$

Ao contrário de Hegel, Marx via a organização política de seu tempo como profundamente irracional. Para ele, a combinação da racionalidade técnica com a irracionalidade social derivada da dominação classista resultava $\mathrm{em}$ relações alienadas de produção. Para Marx, o ideal kantiano e hegeliano da auto-realização somente poderia surgir do excrcício coletivo da razão instrumental em uma comunidade onde as exigências de planejamento fossem transparentes c, contanto que cientificas, fossem percebidas sem contradição por alguns produtores tecnicamente sofisticados. Isso levava Marx a tratar a burocracia de forma periférica c superficial, a negar a necessidade de uma mediação política c a advogar o autogoverno como forma de supcração do aparelho do Estado. Vendo o Estado burocrático como instrumento de uma classe particular, Marx negou o propósito universal que Hegel havia atribuido à Administração Pública. Na concepção marxista, contrariamente, a burocracia era somente a expressão mistificada e mistificadora da alienação social: longe de mediar a sociedade em sua totalidade, a burocracia é, ao mesmo tempo, a expressão $\mathrm{c}$ um instrumento da divisão social.

Para Weber, ao contrário, a burocracia cra o meio inevitável para vincular a razão c o conhecimento e tornar possiveis, ao mesmo tempo, as relações capitalistas. Webcr enfatizou a rclação simbiótica cntre razão $\mathrm{c}$ legitimidade $\mathrm{c}$ afirmou que tal relação possibilitava a dominação so- 
cial na era moderna (capitalismo). Mesmo tendo reconhecido diversos tipos de racionalidade, enfatizou a racionalidade instrumental inerente à ação intencional. Esta racionalidade a serviço da ação intencional (do construtivismo racionalista, tão criticado por Hayck $\mathrm{c}$ Popper $\mathrm{em}$ sua aplicação à sociedade como caminho para o regime totalitário) pressupõe uma concepção social cujos valores últimos se referem mais à eficiência do que à ética. E sua modelação será a "organização legalracional" ou burocracia, que expressa a vantagem da racionalidade instrumental na socicdade moderna. ${ }^{24}$

Os critérios ou exigências desta organização eficiente, na qual se plasmava o ideal de racionalidade instrumental de valor pretensamente universal, são bem conhecidos: seleção $\mathrm{c}$ promoção dos funcionários exclusivamente com base no mérito (superando as concepções patrimonialistas inerentes ao clientelismo politico do sistema de disponibilidade); definição e delimitação das funções oficiais exclusivamentc com base $\mathrm{cm}$ regras impessoais; divisão sistemática do trabalho; hierarquia imparcial de oficios; capacitação dos funcionários com base no conhecimento $\mathrm{c}$ controle de regras técnicas $\mathrm{e}$ normas jurídicas; consistência e regularidade dos atos administrativos que deveriam ser produzidos por escrito; proibição de propriedade dos meios de administração e de adquirir ou transferir os oficios ou cargos públicos e, por último, submissão a um Chefe de Estado clcito ou monárquico. Torna-se desnecessário destacar tanto os serviços prestados à humanidade por esta concepção, como suas grandes inadequações, tanto pcla idealização da realidade que a supõc, como pela ambivalência moral a que pode conduzir (ajudou a constituir o Estado Liberal e Social de Direito, mas também os Estados Fascistas que levaram à Segunda Guerra Mundial).

\section{Tendências na renovação dos paradigmas tradicionais de Direito e o gerenciamento das Administrações Públicas}

Nosso scgundo objetivo consiste em constatar que, tanto o paradigma tradicional de Dircito Administrativo, como o do gerenciamento estão em crise e que existe um amplo e profundo movimento de renovação, constatável no mundo todo. Na Espanha, foi de Luciano Parcjo o mérito de cstabelecer, a partir da corporação acadêmica, a renovação necessária. Dispomos de notícias, mesmo que insuficientes $\mathrm{e} \mathrm{nem} \mathrm{sempre} \mathrm{bem} \mathrm{interpretadas,} \mathrm{sobre} \mathrm{o} \mathrm{questionamento}$ 
e o restabclecimento da doutrina do Dircito Administrativo na França e na Alemanha. Igual fenômeno pode ser observado no âmbito angloamericano. Conforme mostra Galligan, "os administradores percebem hoje que as concepções tradicionais do rule of law $\mathrm{c}$ os valores $\mathrm{e}$ princípios nos quais cla se bascia não são instrumentos adequados para enfrentar os problemas de legalidade e legitimidade do Estado Moderno, e, também, que o desenvolvimento de novos instrumentos necessários está ligado, de forma direta e retilínea, às grandes questões da tcoria política constitucional e organizativa". ${ }^{25}$

A crise ou inadequação de instrumentos procede, $\mathrm{cm}$ primeiro lugar, da contradição entre o Direito Administrativo do "projeto antidiscricional e a revisão judicial" e as exigências de legitimação do Estado Social. Tal contradição, cuja constatação é também uma constante do Direito Administrativo c a Ciência da Administração norte-americana, ${ }^{26}$ é óbvia enquanto o desenvolvimento cconômico e o incrementalismo do gasto social não conhecem limites. Desta forma, o Estado de Direito e o Estado Social puderam coexistir como duas legitimidades paralelas c complementares, que se ignoravam na sua respectiva irrelevância. E, neste contexto, todos os chamados à renovação do Direito Administrativo, mesmo feitos por vozes claramente autorizadas, tiveram pouquíssimo eco doutrinário e influência prática nula. ${ }^{27}$ Porém, como se sabc, a crise econômica dos anos $70 \mathrm{e}$ a correspondente crise fiscal do Estado alteraram completamente a situação. Nos anos anteriores, o desenvolvimento do Estado Social, respondendo a um imperativo constitucional, porém carente de embasamento jurídico, gerou efeitos indescjáveis e perversos na forma de corporativismo social e burocrático, clientelismo político, arbitrariedade e desperdício de recursos. A crise fiscal do Estado revelou todos os desvios citados e introduziu na crise o próprio Estado Social.

A comunidade acadêmica internacional assumiu os desafios colocados por esta crise e, em busca de novas formas de legitimação ou "governabilidade" correspondentes a nosso tempo, está produzindo respostas progressivas importantíssimas no âmbito político $\mathrm{c}$ da teoria organizativa ${ }^{28}$ Particularmente neste último e no do gerenciamento público que lhe corresponde, foi abandonado o tipo burocrático ideal como paradigma universal de racionalidade organizativa, para passar a uma teoria organizativa que se instala na contingência e situa a racionalidade do esquema organizativo e a gestão dos recursos $\mathrm{em}$ função da natureza das tarefas e do tipo de ambiente e nivel tecnológico existentes em cada caso.$^{29} \mathrm{E}$ entre as conseqüências que obviamente decorrem deste fenômeno, queremos ressaltar os efeitos deste trabalho: 
o reconhecimento da racionalidade da fragmentação organizativa das Administrações Públicas (dificilmente compativel com a concepção estatutária da Administração Pública) e a necessidade de produzir novos instrumentos c fórmulas de integração; a necessidade de uma teoria da decisão administrativa $\mathrm{em}$ sua pluralidade, que reconheça diversos graus de discricionariedade necessária e contemple, na referida discricionariedade, a oportunidade de desenvolver novas formas de racionalidade através da incorporação a uma renovada teoria de controle das descobertas da teoria da organização e das políticas públicas; e, finalmente, a urgência de desenvolver novos padrões conceituais e técnicas instrumentais para responder ao desafio das novas relações interorganizativas, públicas e privadas, que são condição da governabilidade do nosso tempo.

Felizmente, todos estes esforços estão sendo correspondidos por uma renovada teoria do Direito Público, já exigida por outras ciências da administração, pela consciência crescente da insuficiência das aproximações não-juridicas do fenômeno administrativo, devido à necessidade de "institucionalizar", isto ć, demarcar, assinalar e traduzir legalmente as novas soluções $c$ instrumentos para a governabilidade ou legitimidade da ordem social e politica atual. A demanda por um Direito Público renovad s pode ser observada na crescente importância dos estudos jurídicos nos planos de estudos do gerenciamento público. E a resposta do Direito Administrativo, mesmo que atrasada, está sendo cada vez mais importante e promissora. Neste sentido, talvez valha a pena referir-se à forma $\mathrm{cm}$ que estão sendo vividos todos os processos na matriz do Direito Administrativo latino, ou seja, na França.

Em 1993, a conhecida revista Politiques et Management Public dedicou um número especial ao tema Droit et Management Public. $\mathrm{O}$ número é encabeçado por um excelente trabalho do psicólogo Patrice Duran, que chegou à conclusão de que, na atual situação, "fica claro que o gerenciamento público necessário não poderá ficar à margem do Direito; porém, o Direito não poderá prescindir do gerenciamento". Para Duran, as dificuldades para a articulação nccessária das duas disciplinas não procedem dos respectivos saberes, cuja sinergia é evidente, e sim do conflito entre os especialistas e suas respectivas posições de poder. A colaboração exige, não obstante, além das inevitáveis discórdias corporativas, que seja superada a concepção simplista da racionalidade instrumental comum tanto ao gerenciamento das "técnicas de gestão" como ao positivismo legalista.

A partir da obra monumental de $\mathrm{H}$. Simon, teve fim a ilusão de um mundo simples e organizado no qual se conjugariam hierarquia e competência, onde o pensamento dirigiria a prática e no qual as 
conseqüências são previsíveis. Longe disso, vivemos no mundo da racionalidade limitada, que leva à instalação do gerenciamento não no mundo do controle e sim no da responsabilidade. Governar deixa de ser o cumprimento de regras e normas para se transformar na gestão de uma ação coletiva cujos agentes controlam margens incvitáveis de libcrdade e na qual a fixação de finalidades e efcitos resulta tão problemática quanto a mobilização dos recursos e a determinação das conseqüências. $\mathrm{O}$ gerenciamento deixa de ser concebido principalmente como planejamento c controle para ser visualizado, acima de tudo, como direção, estratégia ou politica, ou melhor, como ascensão da responsabilidade pela ação coletiva.

O novo gerenciamento público rompe com o gerenciamento cientifico c com a racionalidade instrumental universal do one best way ao afirmar que a direção responsável da ação colctiva não pode ser visualizada somente $\mathrm{em}$ função da aplicação do conhecimento científico aos assuntos práticos; implica também, irremissivelmente, a ação humana, e esta não pode se entender nem ser reduzida à lógica de aplicação da ciência. A direção dos assuntos públicos é tema de conhecimento c de ação; porém, o uso prático do conhecimento científico não pode, por si só, garantir nenhum resultado "cientificamente" preestabclecido. Não há, não houve $\mathrm{c}$ nem haverá um gerenciamento público nem privado que seja a simples aplicação das ciências do gerenciamento, como também não pode scr concebida uma prática juridica $\mathrm{cm}$ função exclusivamente da aplicação das normas legais. Quando fcitos desta forma, os planos da ciência c da ação são confundidos e comete-se o erro de avaliar a prática com os critérios da ciência, ignorando que pertencem a planos diferentes, que o mundo não pode se dobrar à simples vontade e que é perversa a pretensão de substituir a autoridade do politico pela do especialista. A ação tem suas próprias regras, que não são as do pensamento. A ciência do dircito não é o direito prático, da mesma forma que as ciências do gerenciamento não são o gerenciamento $\mathrm{c}$ não podem, por si só, pretenderem definir o que é digno de interesse. Wildavsky não se cansa de lembrar que a "cogitação" pertence a uma ordem diferente da "interação", c que a claboração de soluções intelectuais não significa $\mathrm{cm}$ absoluto sua colocação $\mathrm{cm}$ prática. Como gostava de assinalar, "aqueles quc tomam decisões são os individuos, porém, o que determina os resultados são as interações". ${ }^{30}$

Desta forma, o gerenciamento resulta ser um conjunto de práticas servidas pela reflexão, onde se misturam necessariamente o pragmatismo c o conhecimento científico. Como prática, o gerenciamento se define menos pelas disciplinas científicas em que pode se apoiar (variadas, e contingentes, scgundo a imagem dos 
ingredientes da salada de Dror), do que pela utilização efetiva que faz das mesmas, seguindo combinações diversas em função de cada tipo de problema a ser resolvido. A partir dessa concepção, o Direito tem um papel triplo em relação ao gerenciamento: a) por um lado, é o padrão institucional no qual nascem as organizações c que impede a liberdade de ação dos autores; b) por outro lado é também um instrumento para a obtenção de finalidades especificas; c) finalmente, é também objeto da prática gerencial, à medida que esta, à vista do processo de aplicação ou inaplicação das normas, sc constituirá $\mathrm{cm}$ agente para sua defesa ou sua modificação, tanto $\mathrm{cm}$ relação ao direito instituição, como ao dircito meramentc instrumental.

Para entender devidamente o que foi mencionado, é necessário se situar em uma concepção não positivista do Dircito, isto é, superar uma concepção que identifica a norma juridica com uma ordem que deve ser obedecida; que distingue nitidamente o dircito dos fatos, e que confunde o direito com a burocracia, através da extensão da juridicidade a toda relação intra-organizativa. A metáfora do Dircito como regra do jogo ć válida, porćm com a condição de aceitar que as normas fazem parte do próprio jogo, uma vez que os atores, ainda orientados e constrangidos pelas normas, retêm espaços de liberdade de cuja interação pode resultar a evolução ou a mudança das próprias normas. Sc o Direito pode scr analisado como padrão institucional, como instrumento, como constrição e como recurso, é precisamente porque sua utilização está sempre sujeita a uma apreciação subjetiva. Não existe determinismo cstrito c sobre este dado se crgue tanto a concepção atual do gerenciamento como a concepção renovada do próprio Dircito. ${ }^{31}$ Quanto mais flexivel, incerto e dinâmico sc torna o Direito, mais livres e interdependentes resultam os atores; o Direito fica marcado pela ambigüidade c aleatoricdade, devendo integrar a incerteza $\mathrm{cm}$ scu conceito a partir do reconhecimento de que não existe uma racionalidade prescritiva capaz de guiar, por si só, o comportamento humano.

Tanto o Direito como o gerenciamento estão abandonando a ilusão de um mundo feito de unidade e certeza pelo reconhecimento de um mundo real e atual, cheio de complexidades, diferenças $\mathrm{e}$ incertezas. $\mathrm{O}$ Direito não tem a pretensão de mostrar o que deve ser, mas continua sendo fundamental para definir o espaço do comportamento accitável, dentro do qual os individuos podem se auto-organizar. A partir desta concepção, de sabor claramente neo-institucionalista, o Dircito se transforma de provedor de segurança a redutor de incertezas, permitindo assim incrementar a liberdade dos individuos, cujo desenvolvimento é o espaço específico do direito instrumental. ${ }^{32}$ 
O terceiro $\mathrm{c}$ último propósito consiste $\mathrm{em}$ constatar como a renovação do gerenciamento público, por um lado, e do Direito Administrativo, por outro, está assentando as bases claras e precisas (valores, hipóteses, problemas e métodos) para uma interação fecunda, tanto no plano acadêmico como na prática profissional, na direção pública. Isto deriva da coerência básica que pode ser observada nas linhas de renovação, tanto do Direito como do Gerenciamento Público. A título meramente enunciativo, serão destacadas as seguintes linhas:

Em primciro lugar, como conseqüência do abandono da universalidade da racionalidade organizativa burocrática, a nova racionalidade gerencial estabelece a necessidade de uma diversificação organizativa $\mathrm{e}$ do regime jurídico das Administrações Públicas. A velha concepção da Administração como pessoa juridica única dotada de um Estatuto juridico torna-se altamente inadequada, já que a diversidade de tarefas, ambientes e tecnologias a serem desenvolvidos pela organização, em cada caso, estabelece a racionalidade de uma diversidade organizativa, de privilćgios administrativos, do regime de recursos humanos $\mathrm{e}$ financciros $\mathrm{c}$ das formas de atuação $\mathrm{c}$ relação com os cidadãos ou outras organizações públicas e privadas. Definitivamente, o Direito Administrativo deve se tornar, necessariamente, mais complexo e plural, tal como já aconteceu com o gerenciamento desde seu ingresso na teoria da contingência, e assumir o risco da fragmentação derivado da nova racionalidade $\mathrm{e} o$ desafio de encontrar novas formas e mecanismos de integração, cujo aperfeiçoamento e desenvolvimento são uma das grandes tarefas comuns ao Direito e ao Gerenciamento Público renovados.

Em segundo lugar, o Gerenciamento Público abandonou o conceito e a técnica do planejamento normativo c a rígida separação entre plancjamento e exccução que dela decorria, antecipando, desta forma, o caminho que o Dircito Administrativo começa a percorrer atualmente ao revisar a tcoria tradicional da programação da Administração pela Lei c abandonar o correspondente conceito de Administração como execução normativa para substituí-lo pela idéia básica de disposição de recursos (humanos, financeiros, tecnológicos) para fins, $\mathrm{em}$ padrões normativos, detcrminados $\mathrm{e} \mathrm{cm}$ diversos ambientes, porém, cada vez mais mutantes e complexos. A Lci não somente é a norma abstrata geral que contém $\mathrm{cm}$ si a ratio de toda futura decisão administrativa, 
mas, tambćm, a apropriação por cada Administração particular de um âmbito de decisão próprio e autônomo, embora racionalmente diferente em cada caso, pcla própria contingência anteriormente mencionada da nova racionalidade organizativa.

Em terceiro lugar, o abandono pelo gerenciamento da ilusão sem fundamento de que todo comportamento organizativo somente $\dot{c}$ racional na medida em que se encontre previamente previsto e normatizado, com a conseqüente revalorização da autonomia c responsabilidade dos gerentes e do pessoal $\mathrm{cm}$ geral, tem correspondência com o atual movimento de revalorização da discricionariedade e da responsabilidade subjetiva no Direito Administrativo. Felizmente, já está estabclecida a clara distinção entre discricionaricdade c arbitrariedade, mesmo que a distinção contribua pouco para a construção de uma nova e mais necessária tcoria jurídica da discricionariedade. Está sendo também cada vez mais accita a idéia do pluralismo ou diversidade da discricionariedade necessária, devido à diversidade da base racional, para a determinação do optimum da discricionariedade em cada situação. Com maiores dificuldades, vai se impondo a idéia da necessidade de participação dos interessados (incluidos os portadores ou os que expõem interesses difusos). Porém, todas cstas contribuições só limitam o problema jurídico, que ć a chave do que será feito com o núclco cada vez maior de decisões discricionárias. Neste sentido, a accitação c a reinserção da discricionariedade no Dircito passam pelos vários caminhos até agora propostos, sendo que nenhum deles consiste $\mathrm{cm}$ situar a discricionariedade no âmbito político, climinando plenamente a revisão jurisdicional e não admitindo outro controle que não seja o parlamentar e o político. Pclo contrário, a grande tarefa jurídica está em definir a contribuição do Dircito para o bom aproveitamento da oportunidade de racionalidade que a discricionariedade supõc. E, neste sentido, as vias a serem exploradas são diversas: desde a institucionalização do controle de gestão c a avaliação de programas, ao fortalecimento dos Tribunais de Contas ou à criação de instâncias para supervisionar a gestão c cxigir responsabilidade pessoal, sem esquecer a necessidade de um restabelccimento das relações entre discricionariedade e poder judicial.

Em quarto lugar, o abandono da idéia de plancjamento normativo e sua substituição pelos conceitos e técnicas de análise e de gestão estratégica, por parte do gerenciamento, corresponde a uma nova percepção do papel do Dircito Administrativo, já não somente como modelo, mas, também, como instrumento de ação para fins ou transformações especificas. Desta forma, o Direito se configura, em grande parte, como instrumento ou recurso a mais entre a variedade de 
recursos ou formas de ação, entre as quais se deverá optar de forma diversa e racionalmente estabelecida $\mathrm{em}$ cada caso. Fala-se, desta forma, na utilização seletiva e estratégica do Direito, o que estabelece desenvolvimentos promissores da teoria da produção das normas jurídicas, capazes de situá-la além do plano formal ou procedimental no qual sc encontra atualmente. Particularmente, a conexão da teoria jurídica com a teoria econômica das regulamentações e análises decisórias da teoria da organização parecem ser caminhos promissores que já começaram a ser percorridos.

Em quinto lugar, à accitação pelo gerenciamento da teoria econômica dos bens públicos, corresponde a aceitação pelo Direito Administrativo de que a lei não pode fixar, de forma precisa, os fins, interesses e objetivos públicos, assim como estes, mesmo quando continuem sendo responsabilidade indeclinável dos poderes públicos, dependem cada vez mais da relação de tais poderes entre si e da colaboração dos cidadãos. O desenvolvimento das teorias e técnicas de construção e gestão de redes interorganizativas, a partir do gerenciamento público, ou a construção de um marketing público a partir da configuração dos usuários como clientes ou até mesmo a partir da proclamação dc um novo princípio de "receptividade", corresponde ao interesse crescente do Direito Administrativo pelas relações interadministrativas, as diferentes formas convencionais ou participativas de gestão decorrentes do ato administrativo tradicional ou o desenvolvimento do posicionamento jurídico do cidadão perante os serviços públicos a serem prestados.



\footnotetext{
' A generalidade e o alcance do fenômeno em todas as democracias avançadas são percebidos em uma excelente tese de doutoramento, não por acaso nascida e produzida entre ESADE e DEUSTO, cujo autor é Koldo Echebarria, e tem o significativo titulo de La Administración Pública en la era del management. Reflexiones sobre una década de modernización administrativa. Sobre a importância do gerenciamento na chamada Administração para o Desenvolvimento, basta levar em considerą̧a que o enfoque "gerenciamento" é claramente dominante nas Naçðes Unidas (MDP, Management Development Program, do PNDU, Programa de Naciones Unidas para el Desarrollo), no Banco Mundial (que dispõe de uma Divisão de Gerenciamento público cada vez mais influente), no Banco Interamericano de Desenvolvimento e na OCDE, pela mesma razão. Sobre a importância do gerenciamento no movimento da reforma administrativa
} 
globalmente considerada, ver CAIDEN, G. Administrative Reform Comes of Age, Berlim: Walter the Gruyter, 1991.

${ }^{2}$ A literatura sobre a relação entre o Estado do Bem-Estar e os valores da eficácia e eficiência é abundante e muito conhecida, por isso nos dispensamos da sua reprodução, em benefício próprio do leitor. Talvez valha a pena, em compensação, fazer referência a algum trabalho sobre a relevância da "qualidade" do setor público para a competitividade dos respectivos paises. Trata-se de um assunto, sem dúvida, relacionado com as transformações da ordem econômica internacional. A pergunta inicial (por que uma nação se converte na sede dos mais vantajosos competidores?) foi formulada por Porter em uma obra que já é um clássico na matéria (Porter, M. E. The Competitive Advantage of Nations, New York: The Free Press, 1990).

O estudo do impacto positivo ou negativo das políticas estatais na competitividade das empresas é um tema que preocupa principalmente a partir da crise econômica dos anos 70 (por exemplo, Bacon, R. e Eltis, W. Britain's Economic Problems. London: Mc.Millan Press, 1976, desenvolveram a tese de que os excessos na construção do Estado do Bem-Estar prejudicaram gravemente a competitividade do Reino Unido, uma vez que o desenvolvimento da Administração social absorveu demasiadamente o excedente empresarial impedindo um grau suficiente de investimento, produtividade e exportação; inversamente, os comentaristas costumam elogiar a política japonesa de apoio às empresas e á competitividade, considerada já como uma diretriz de "reforma administrativa" (Veja a respeito WRIGHTS D. e Sakural, Y. "Administrative Reform in Japan...", Public Administration Review, 1987, vol.47, pp. 121 e ss.

A competitividade como diretriz de reforma administrativa aparece hoje em diversos documentos oficiais de partidos políticos. Associaçðes empresariais, organismos internacionais (veja, por exemplo, o conhecido manifesto de Clinton Mandate for Change, ed. por Marshall, W. e Schram, M. The Progressive Policy Institute, New York: Berkley books, 1993, e especialmente os trabalhos de David Osborne incluidos no mesmo; ou, entre nós, o "Estudo Introdutório" do n. 1, 1992, da Revista del Instituto de Estudios Económicos, dedicada monograficamente à revisão do Setor Público nos anos 90; a mesma inquietação é expressa no documento do Governo francês Comissariat Général du Plan - Rapport de la Commission sur l'Efficacité de l'Etat: Le Pari de la Responsabilité, Paris: La Documentation Française, 1989 ou o interessante documento do Instituto do Desenvolvimento Econômico do Banco Mundial, "International Competitiveness, Interaction of the Public and the Private Sector", cditado por Irfan, Ull Haque, The World Bank, Washington DC, 1989).

Especial relevo teórico tem a tentativa de alguns autores de precisar o conceito de "ecoestrutura" como integrador de todas as variáveis determinantes da competitividade internacional, cujo manuseio depende, principalmente, do Estado (Davidson, W. Ecostructures and International Competitiveness" in Negand, A. c SAVAR, A., International Strategic Management, Lexington (MA): Lexington books, 1989) idéia que, sob uma cu outra formulação, está obtendo um acolhimento generalizado, como se pode observar no recente livro de Drucker, P. Post-Capitalist Society. New York: Harper Collins, 1993.

3 Adotamos aqui o significado dado ao termo "instituição" pelo novo institucionalismo presente, tanto no campo econômico, como no sociológico e na teoria da organização. O ponto chave de partida, sob o nosso ponto de vista, consiste em distinguir entre os conceitos de "instituição" e de "organização" e entre as aproximações e métodos científicos relativos à compreensão e à intervenção $\mathrm{cm}$ cada uma destas realidades. Sobre o tema podem ser vistas minhas notas 
introdutórias ao livro de $\mathrm{K}$. Echebarria, no prelo, que constitui uma reelaboração de sua tese de doutoramento.

"A "especificidade" cientílica do gerenciamento público è reconhecida não só pelos acadêmicos que lideram internacionalmente esta árca do conhecimento, mas, também, pelos que lideram o gerenciamento empresarial privado. A certeza e conhecimento deste dado dispensam as citaçðes bibliográficas, mas recomendo a leitura do ponto "Why Governments can't be run like a business" da brilhante obra de Osborne, D. e Gaebler, T. Reinventing Government, How the Entreprenencial Spirit is Transforming the Public Sector. Addison-Wesley, 1992, pp.20 e ss.

${ }^{s}$ Referimo-nos a um fenómeno que não é exclusivamente espanhol. Mais adiante teremos oportunidade de nos dedicar especificamente a ele. No momento, cabe citar o autor norte-americano que, recentemente e de forma brilhante, não somente argumentou que se o Direito Administrativo não abandona o projeto antidiscricional tradicional, irá se converter $\mathrm{cm}$ uma disciplina irrelevante, quando não obstacularizadora das transformaçð̃es do Estado de nosso tempo, tendo proposto, ainda, umas linhas interessantes para o desenvolvimento de um novo paradigma: Eder, C. JR. Administrative Law Rethinking Judicial Control of Bureaucracv, New Haven and London: Yale University, 1990.

${ }^{6}$ Mintzberg, H. Mintzberg y la Dirección, Barcelona: Diaz Santos, 1991, p.32. Uma interessante aplicação das teorias de Kuhn no âmbito do gerenciamento encontra-se em Barker, J., The Future Edge, New York: William Morrow, 1992.

${ }^{7}$ Uma descrição sucinta, que pode ser considerada geralmente aceita, é a exposta sob a rubrica "causas da crise do Estado como sistema de Direito Público" em Parejo, L. Crisis y Renovación en el Derecho Público, Madrid: Centro de Estudios Constitucionales, 1991, pp.17-29.

${ }^{8}$ Um bom exemplo é constituido, no campo do Direito da Função Pública, pelo estreitamento e desenvolvimento dos conceitos angulares de "mérito e capacidade". Como demonstrou em sua tese de doutoramento Perez, M. lgualdad, Mérito y Capacidad en el accesso al empleo público professional (Los casos de Estados Unidos. Francia y Espana), hoje fica sem sentido trabalhar com um conceito de mérito que não acolha as descobertas realizadas neste campo pelo gerenciamento dos recursos humanos.

${ }^{9}$ Loschak, D. "Le droit administratif, rempart contre l'arbitraire", Pouvoirs, vol.46, 1988, pp.43-55. Crozier, M. Etal Modeme, Etat Modeste. Paris: Fayard, 1987. CAlllosse, J. "La modernisation de I'Etat", L'Actualité Juridique -Droit Administratif, 20 de novembro 1991, p.759; ver também do mesmo autor, "L'Administration française doit-elle s'évader du droit administratif pour relever le defi de l'eflicience?", Revue Politiques et Management Public, vol.7, 1989, p.163 e ss. Willke, H, "Le cou du principe de la legalité", Moran, C. (ed.). Figures de la legalité, Paris: Publisud, 1992, pp.127 e ss.

${ }^{10}$ Neste sentido, ver também Bryner, G. Bureaucratic Discretion Law and Policy in Federal Regulatory Agencies, New York: Pergamon Press, 1987.

"Steel.e, G. "Private Lawyers, public law: administrative law in the making", $\mathrm{Ca}$ nadian Public Administration, vol.35, n. 1, 1992, pp.l e ss.

${ }^{12}$ Davis, K.C. Administrative Low Test, $3^{3}$ ed., St. Paul, Minn: Key West Publishing, 1972, p. 2 .

${ }^{13}$ A atual teoria organizativa vem insistindo na importância da "institucionalização" das mudanças ou reformas pretendidas. Este conceito refere-se à manutenção das mudanças, à garantia de sua permanência no tempo, à sua interiorização pelos agentes do sistema como uma das regulamentaçðes efetivas do mesmo (Goodman, P. e outros, 
Barzeman, M. e Conlon, E. "Institutionalisation of Planned Organisational Change", Staw, B. e Cummings, L. (eds), Research in Organisation Behaviour, vol.2, Greenwich, Con: Jar Press, 1980, pp. 215 e ss. Crozier, M. e Fridberg, E. L'acteur et le système, Paris: Editions du Seuil, 1977). Embora a análise mais aguda do conceito de instituição e sua importância nos processos planificados de mudança administrativa pareçam estar em MARCh, J. e OLSEN, J. Rediscovering Institutions, New York: The Free Press, 1989.

${ }^{14} \mathrm{O}$ tratamento juridico dos princípios de eficácia e de eficiência encontra-se marcado por sua confusão com a teoria tradicional da eficácia das normas e atos administrativos. A construção jurídica dos princípios de eficácia e eficiência, como principios constitucionais independentes, é ainda uma tarefa pendente que, do nosso ponto de vista, não poderá se desenvolver sem a incorporação ao Direito público de conceitos procedentes das ciências da gestão. Alguns trabalhos recentes começam a caminhar nesta direção: BETTINI, R, ll circulo vicioso legislativo, efficacia del diritto ed efficienza degli apparati publici in ltalia, Milano: Angeli, 1983, e PAREJo, L, "La eficacia como principio jurídico de actuación de la Administración Pública", Revista de Administración Pública, n.218-219, 1989, pp.15 e ss.

${ }^{13} \mathrm{~A}$ inevitável tensão entre os diferentes valores e principios constitucionais da organização e gestão administrativa, tem sido expressivamente estruturada por Downs, G. e LARKEY, P., The Search of Government Efficiency. New York: Random House, 1986.

${ }^{16}$ Deveria-se abandonar definitivamente o engano intelectual que consiste em opor burocracia e gerenciamento, racionalidade burocrática e racionalidade gerencial como um antagonismo insolúvel. Esta oposição está associada, nos que a formulam, à identificação das burocracias com as "buropatologias" e da racionalidade gerencial ou gerenciamento com a ernpresa privada eficiente. Esta maneira de proceder $\mathfrak{e}$ intelectualmente incorreta, por mais difundida que seja. Ver Mintzberg, H. La Estructuración de las Organizaciones, Barcelona: Ariel Gestion, 1984.

"Ver o reconhecido artigo de Arthurs, H., "Rethinking Administrative Law. A Slightiy Dicey Business", em Osgood Hall Law Journal, vol. 17, n.1, 1979, incluindo, depois, a excelente compilaça de Galligan, D. Administrative Law. The International Library of Essays in Law and Legal Theory, Aidershot: Dartmonth, 1992 , p.17 e ss. No mesmo sentido, JowelL, J. "The legal control of administrative discretion" em Galligan, op.cit., p. 250 .

${ }^{18}$ A bifurcação inicialmente estruturada por Dicey entre Direito e discricionariedade é levada ao seu extremo lógico econômico-jurídico na monumental obra de Hayek, na qual encontramos a exposição mais coerente, profunda e honesta das "contradições" ou incompatibilidade entre o "rule of law" e o "welfare state". A exposição mais completa e sistemática da teoria do Direito de Hayek e de sua funcionalidade com a sociedade de economia de mercado pode ser encontrada nesse monumento ao talento humano que é HAYEK, F, Law. Legislation and Liberty, Londres: Routledge and Kegan Paul, 1982.

19 Weber, M, Economia y Sociedad, México: Fondo de Cultura Económica, 1964, p.56. Uma exposição sistemática e fiel do pensamento burocrático weberiano, nem sempre corretamente reproduzido, pode ser encontrada na obra de Nieto, A. La Burocracia. El Pensamiento Burocrático, Madrid: Instituto de Estudios Administrativos, p.581 e ss.

${ }^{20}$ Ver uma breve e sintética exposição dos principais autores desta linha de pensamento em Mouzelis, N. Organización y Burocracia, Barcelona: Ediciones Península, 1989, p.85 e ss.

${ }^{21}$ No âmbito latino-americano, todos estes extremos têm sido reiteradamente expostos em sucessivos e repetidos trabalhos, de B. Kliksberg, e J. Sulbrandt. Uma 
apresentação sistemática do assunto pode ser vista em KLIKSBERG, B. El Pensamiento Organizativo, Buenos Aires, 1992, p.123 e ss.

${ }^{22}$ Pode-se ver MIEWALD, R. "The origins of Wilson's Thought. The german tradition and the organic state", em RABIN, J. e Bowman, eds. Politics and Administration: Woodrow Wilson and American Public Administration, New York: Marcel Dekker, 1984, pp. 17-30. Na mesma obra pode ser visto também o trabalho de CAIDEN, G. "In search of an Apolitical Science of American Public Administration", pp.51-78.

${ }^{23}$ Sobre os diversos conceitos de racionalidade envolvidos nas diversas abordagens da Administração Pública pode-se ver White, J. "Images of Administrative Reason and Rationality: The Recovery of Practical Discourse", em Kass, H. e CATroN, B. eds. Images and Identities in Public Administration. Londres: Sage, 1990.

${ }^{24}$ Uma exposição das raizes teóricas da concepção da Administração Pública como instrumento racional pode ser encontrada em Sossin, L. "The politics of discretion: toward a critical theory of public administration", em Canadian Public Administration, vol.36, 1993, pp.364-391.

25 Ver Galligan, ob. cit.

26 Ver, por exemplo, a crônica histórica que faz do tema BerkLEy, G. The Craft of Public Administration, 6' edición, Boston: Ailen and Bacon, cap. 11.

${ }^{27}$ O destino do trabalho de Nieto, $A$. "La vocación del Derecho Administrativo en nuestro tiempo", Revista de Administración Priblica, vol.76, 1975, pp.9 e ss., tão intelectualmente motivador como carente de impacto, é semelhante ao de trabalhos anteriores em outros países mais avançados (ver, por exemplo, o trabalho pioneiro de Jones, H. "The Rule of Law and the Welfare State", em Columbia Law Review n. 58, 1958, pp. 143 e ss. Poucas vezes foi colocada tão claramente como ai a verdade da observação de Kuhn, segundo a qual para que seja produzida uma mudança de paradigmas não basta que se evidenciem as contradiçðes e insuficiências do ainda dominante e, sim, é necessário que a comunidade científica disponha de um paradigma alternativo (que resulte socialmente mais exigido e mais relevante), uma vez que, na ciência como na vida, continua prevalecendo a frase de Bacon na qual a verdade nasce mais facilmente do erro do que da confusão.

${ }^{28}$ No âmbito da teoria política e do gerenciamento público pode-se ver, por exemplo, a série de trabalhos incluidos em Koolman, J. ed. Modern Governance and New Goveriment Society Imteractions, Londres: Sage, 1993.

${ }^{29} \mathrm{Um}$ excelente relato deste interessantíssimo processo na área da teoria organizativa e de sua relação com a crise do Estado do Bem-Estar pode ser visto em Echebarria, K. ob. cit., capitulos II e III.

${ }^{30}$ Wu.davsky, A. The Art and Craft of Policy Analysis: Speaking Truth to Power. London: McMilian, 1976.

${ }^{31}$ Sob esta concepção do Direito pode ser vista a grande obra de HAYEK, Law, Legislation and Liberty. Londres: Routladge and Kegan Paul, 1973. Mais recentemente, VAN DER KeRChOVE, M. e Ost, F. Le système juridique entre ordre et désordre. Paris: PUT, 1988; Revnaud, J. D. Les règles du jeu. l'action collective et la régulation sociale, Paris: Anmand Collin, 1989; também os trabalhos incluidos em Ost, F. e VAN DER KeRChove, M. eds., le jeu: un paradigme pour le droir. Paris: LGDJ, 1992.

32 Duran, P. "Piloter l'action publique, avec ou sans le droit?", em Politiques et Management Publique, dez. 1993. 
Resumen

Abstract

Direito e gerenciamento nas administrações públicas - Notas sobre a crise e renovaçāo dos respectivos paradigmas

Joan Prats i Calalá

A partir da constatação da penetração do gerenciamento no campo da Administração Pública, o autor afirma a possibilidade e a necessidade do diálogo entre Direito Administrativo e Gerenciamento Público, atribuindo a aparente oposiçąo entre estes campos do conhecimento à assincronia entre os movimentos de renovação dos paradigmas hegemônicos em ambas as áreas. A coerência do modelo tradicional do Direito Administrativo, baseado no "projeto antidiscricional", com o modelo de gerenciamento representado pela teoria clássica da burocracia e da ordenação científica do trabalho, sugere que a reformulação dos respectivos paradigmas pode abrir caminho para uma progressiva interação, nos planos normativo e empirico, do Direito Administrativo e do gerenciamento na gestão da máquina pública.

Derecho y gerencia en las administraciones públicas - Notas sobre la crisis y la renovación de los respectivos paradigmas

Joan Prats i Calalà

A partir de la constatación de la inserción de la gerencia al campo de la Administración Pública, el autor afirma la posibilidad y la necesidad del diálogo entre el Derecho Administrativo y la Gerencia Pública, atribuyendo la aparente oposición entre estos campos del conocimiento al asincronismo entre los movimientos de renovación de los paradigmas hegemónicos en ambas las áreas. La coherencia del modelo tradicional del Derecho Administrativo, basado en el "proyecto anti-discrecional", con el modelo de gerencia representado por la teoria clásica de la burocracia y de la ordenación científica del trabajo, supone que la reformulación de los respectivos paradigmas puede crear condiciones hacia una progresiva interacción, en los niveles normativo y empirico, del Derecho Administrativo y de la Gerencia Pública.

Law and management in Public Administration - Notes on the crisis and renewal of the corresponding paradigms

Joan Prats i Calalá

Starting from the conclusion that management has permeated public administration, the author states that a dialogue between public law and public administration is likely; attributing the seemingly opposition between these two fields of knowledge to the imbalance between the movements of renewal of hegemonic paradigms in both areas. The consistency of the traditional Administrative Law model, based upon an "anti-discretional project", with the management model represented by the classical bureaucracy theory and the scientific work organisation, suggests that the reformulation of corresponding patterns may open the way for a progressive interaction of Administrative Law and management, both in the normative and empirical plans. 
Artigo publicado na Revista do CLAD - Reforma y Democracia, ${ }^{\circ} 3$, p. 89-114, em janeiro de 1995. Traduzido por Carolina Andrade, com autorização dos editores. 